may relieve symptoms, and both strengthening and endurance exercise is of benefit to patients with mild and moderate osteoarthritis. Referral to exercise training appears to be the most useful option but home based programmes are effective too. ${ }^{56}$ Training improves muscle strength and joint mobility, but the condition is progressive and training offers only a temporary respite in the inevitable decline in function. ${ }^{7}$ Facilities for getting people started and providing support through a programme of exercise training are not commonly available in the United Kingdom so referral is rarely an option. Acupuncture may reduce pain and improve both physical function and health related quality of life. ${ }^{\text {w3 }}$ Taping may also be a useful short term and intermittent intervention, although arranging weekly taping by a physiotherapist might prove difficult in the NHS. ${ }^{8}$ Topical anti-inflammatory applications are of some help, and patients often try glucosamine and chondroitin, which have been shown to be of benefit and can be sold directly to patients. ${ }^{9-11}$

Intra-articular injections are effective. Notable improvements are seen in the short term (two weeks), and in some longer term studies (16-24 weeks). ${ }^{12}$ But the short term benefits can be important. Normal lives are a patchwork of work, leisure, holidays, weddings, and other life events. Short term benefit from an intraarticular injection may give sufficient temporary improvement to allow a patient to go on holiday, take part in a family event, or simply enjoy getting outdoors during summer. The pain relief can be almost immediate and the improvement in mobility magical. The benefit, however short term, can make such a difference. No one knows the long term effects of repeated injections although they seem to be safe over two years. Surgery is ultimately the preferred option. But, for most patients the most difficult period is between onset of the symptoms and the point when surgery becomes necessary.

Thankfully, surgery does offer the ultimate answer in the severely osteoarthritic knee. ${ }^{\mathrm{w} 4}$ The results are good in about $90 \%$ of patients, with improvement in pain, functional status, and overall health related quality of life, and $85 \%$ of patients are satisfied with the outcome. The strongest evidence is in studies with two years' follow up, but the results are also positive in studies with five to 10 years' follow up. The overall complication rate of $5.5 \%$ includes infection, deep vein thrombosis, and poor wound healing and a further $0.5 \%$ die during surgery. The revision rate after five or more years is $2 \% .{ }^{\mathrm{w} 5}$ Total knee replacement is a good option when other strategies fail, in patients with chronic pain and functional limitation.

The slightly swollen aching knee usually gets worse. We may slow the inevitable decline in function and provide short term symptomatic relief. Prescription medicines offer some benefit, but patients may be justified in self medication with glucosamine and chondroitin. Intra-articular injections do offer short term benefit and, although general practitioners have been reluctant to inject, perhaps improved training may encourage a more active approach. Exercise training, guided by a physiotherapist, may also delay decline.

Domhnall MacAuley general practitioner

Hillhead Family Practice, Belfast BT11 9FZ

(domhnall.macauley@ntlworld.com)

Competing interests: None declared.

Bjordal JM, Ljunggren AE, Klovning A, Slørdal L. Non-steroidal anti-inflammatory drugs, including coxibs, in osteoarthritic knee pain: a meta-analysis of randomised placebo-controlled trials. BMJ 2004; 329:1317-20.

2 British Medical Association, Royal Pharmaceutical Society of Great Britain. British national formulary. London: BMA, RPS, 2004 (No 48).

Zhang W, Jones A, Doherty M. Does paracetamol (acetaminophen) reduce the pain of osteoarthritis?: a meta-analysis of randomised controlled trials. Ann Rheum Dis 2004 63:901-7.

4 Shrier I. Muscle dysfunction versus wear and tear as a cause of exercise related osteoarthritis: an epidemiological update. Br J Sports Med 2004:38:526-35.

5 Fransen M, McConnell S, Bell M. Exercise for osteoarthritis of the hip or knee. Cochrane Library, Issue 3. Chichester: John Wiley, 2004

Thomas KS, Muir KR, Doherty M, Jones AC, O'Reilly SC, Bassey EJ Thomas KS, Muir KR, Doherty M, Jones AC, O'Reilly SC, Bassey EJ.
Home based exercise programme for knee pain and knee osteoarthritis: randomised controlled trial. BMJ 2002;325:752

7 Van Baar ME Dekker J, Oostendrorp RA et al. Effectiveness of exercise in patients with osteoarthritis of hip or knee: nine months follow up. Ann Rheum Dis 2001;60:1123-30.

8 Hinman RS, Crossley KM, McConnell J, Bennell KL. Efficacy of knee tape in the management of osteoarthritis of the knee: blinded randomised controlled trial. BMJ 2003;327:135

9 Mason LR, Moore A, Edwards JE, Derry S, McQuay HJ, Topical NSAIDs for chronic musculoskeletal pain: systematic review and meta-analysis. for chronic musculoskeletal pain: systematic review and meta-analysis

10 Towheed TE, Anastassiades TP, Shea B, Houpt J, Welch V, Hochberg MC. Glucosamine therapy for treating osteoarthritis. Cochrane Library, Issue 3 , 2004. Chichester: John Wiley.

11 McAlindon TE, LaValley MP, Gulin JP, Felson DT. Glucosamine and chondroitin for treatment of osteoarthritis: a systematic quality assessment and meta-analysis. JAMA 2000;283:1469-75.

12 Arroll B, Goodyear-Smith F. Corticosteroid injections for osteoarthritis of the knee: meta-analysis. BMJ 2004:328:869.

\title{
Dealing with editorial misconduct
}

\author{
New code of conduct for editors is a first step in self regulation
}

66] am that wicked editor," announced the email from Richard Smith, then editor of the BMJ, to members of the World Association of Medical Editors (WAME) on their listserve two years ago. An aggrieved author had, at Smith's suggestion, complained to WAME's ethics committee after the $B M J$ went back on its promise to publish a paper. When the anonymised case was posted on the listserve, opinion from WAME's members was unanimous-the editor in question had behaved wrongly and the journal should
This case is important. Although of a different order of magnitude than serious cases of editorial misconduct that have been uncovered over the past 10 years, ${ }^{1}$ it may be the first example of self regulation by journal editors. An author complained, a body of editors responded, and right-as perceived by those editors-was done.

Editors have traditionally enjoyed power without well codified responsibilities. They decide what gets published and they control an author's right of reply. Much effort has been focused, largely by editors, 


\section{The code-key points \\ Editors should \\ - Ensure the quality of published material \\ - Publish descriptions of peer review and appeals processes \\ - Publish corrections and apologies where necessary \\ - Retract fraudulent or erroneous articles \\ - Publish cogent criticisms from readers \\ - Stand by decisions to publish papers unless serious problems are found \\ - Ensure research articles conform to ethical guidelines \\ - Obtain written consent to publish from patients described in case reports \\ - Maintain confidentiality of submitted material \\ - Keep editorial and commercial decisions separate \\ - Declare their own and other people's conflicts of interest \\ - Deal properly with complaints \\ - Make all reasonable efforts to ensure that allegations of misconduct are properly investigated}

on what constitutes good and bad behaviour on the part of authors and peer reviewers. ${ }^{2}$ Far less attention has been paid to the behaviour of editors themselves. Over the years, the International Committee of Medical Journal Editors has included guidance to editors in its Uniform Requirements for BioMedical Publication, ${ }^{2}$ and in 2001 WAME produced a statement on the responsibilities of editors. ${ }^{3}$ This week, building on these initiatives, the Committee on Publication Ethics (COPE) launches a new code of conduct for editors (www.publicationethics.org.uk).

The code, initiated by Richard Smith and Michael Farthing, former editor of Gut, comprises a set of standards for good editorial conduct (box).

But the code takes editorial responsibility beyond these-what may be considered basic hygiene measures. It places a new and potentially onerous duty on editors to pursue allegations of research misconduct. Editors are in a unique and difficult position. They are often the first to hear concerns about a paper's integrity. Researchers may contact the journal to say that they should have been, or should not have been, included as authors. A peer reviewer may spot that a paper, or something very similar, has been published by the same authors elsewhere, or that it plagiarises their own or someone else's work, or that the authors have failed to declare important conflicts of interest, or that the data are just too good to be true.

Editors have no mandate, and usually inadequate resources, to investigate such cases themselves. In view of this, they may be tempted to take the route of least resistance, especially when allegations are made in relation to a paper that has landed on their desk but has not yet been published in their journal. A published paper is clearly within the editor's jurisdiction and may be corrected or retracted. But what of allegations about an unpublished paper? Rather than embarking on a potentially troublesome and protracted investigation, an editor may be tempted simply to reject the paper on other grounds. COPE takes the view that this is not acceptable. The code specifically calls upon editors to take seriously their role as guard- ians of biomedical science and to make all reasonable efforts to ensure that allegations, whether relating to published or unpublished papers, are properly investigated.

Supporting editors in this difficult but crucial aspect of their work is one of COPE's main objectives. It does this by publishing guidance and providing a forum in which editors can discuss individual, anonymised cases. COPE now has 245 member journals and has heard over 200 cases since it was established in 1997. The summaries of these cases, along with COPE's recommendations, now form a unique publicly accessible archive on COPE's website (www.publicationethics.org.uk).

COPE's other main objective is to promote the setting up in the United Kingdom of an agency to which allegations of serious research misconduct can be referred. Such agencies already exist in Australia, Denmark, Finland, Norway, and the United States reflecting the seriousness with which those countries take the threat of research misconduct. ${ }^{5}$ Efforts to establish a similar agency in the United Kingdom are at long last beginning to bear fruit: Universities UK, the Department of Health, and the NHS are now working together on a framework to establish a panel for research integrity. COPE hopes that cases referred to such a body will receive serious attention and prompt action.

The COPE code stops short of compulsion. No sanctions exist for editors who breach the code. We felt that this would be counterproductive and impossible to enforce, given that COPE has no legal jurisdiction. At most, editors who seriously breach the code will be removed from COPE's list of members. But the code does provide a mechanism for people to refer complaints against editors who are members of COPE. Complaints can be referred by readers, authors, peer reviewers, other editors, or publishers, but COPE will only consider complaints that have been through the journal's own complaints procedure-in effect providing its members with a mechanism for dealing with unresolved and difficult cases.

The two professions most closely allied to medical journal editing, medicine and the press, have well established systems for self regulation. But self regulation is a privilege not a right. It brings with it responsibilities to establish and enforce standards of good practice. The COPE code of conduct is a first step.

Fiona Godlee head of BMJ Knowledge

BMJ Publishing Group, London WC1H 9JR (fgodlee@bmjgroup.com)

Competing interests: FG is chair of the Committee on Publication Ethics.

1 Rennie D. Misconduct and journal peer review. In Godlee F, Jefferson T, eds. Peer review in health sciences. 2nd ed. London: BMJ Books, 2003.

2 Uniform requirements for manuscripts submitted to biomedical journals: writing and editing for biomedical publication. www.icmje.org/icmje.pdf (accessed 22 Nov 2004).

3 The responsibilities of medical editors: a statement by the World Association of Medical Editors. www.wame.org/wamestmt.htm\#responsibilities (accessed 22 Nov 2004)

4 Smith R. Misconduct in research: editors respond. BMJ 1997;315:201-2.

5 Rennie D. An American perspective on research integrity. BMJ 1998; 316:1726-8. 